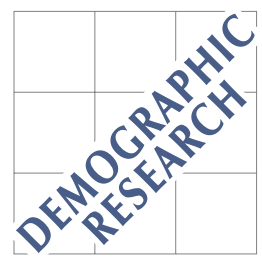

Demographic Research a free, expedited, online journal of peer-reviewed research and commentary in the population sciences published by the Max Planck Institute for Demographic Research Konrad-Zuse Str. 1, D-18057 Rostock · GERMANY www.demographic-research.org

DEMOGRAPHIC RESEARCH

VOLUME 26, ARTICLE 14, PAGES 319-330 PUBLISHED 18 APRIL 2012

http://www.demographic-research.org/Volumes/Vol26/14/

DOI: 10.4054/DemRes.2012.26.14

Formal Relationship 17

\title{
Stationary populations with below-replacement fertility
}

\section{Carl P. Schmertmann}

(c) 2012 Carl P. Schmertmann.

This open-access work is published under the terms of the Creative Commons Attribution NonCommercial License 2.0 Germany, which permits use, reproduction \& distribution in any medium for non-commercial purposes, provided the original author(s) and source are given credit. See http://creativecommons.org/licenses/by-nc/2.0/de/ 


\section{Table of Contents}

$1 \quad$ Relationship $\quad 320$

2 Proof $\quad 320$

$3 \quad$ History and related results 322

$4 \quad$ Numerical examples: Austria 323

$5 \quad$ Applications $\quad 324$

$6 \quad$ Acknowledgements $\quad 328$

$\begin{array}{lr}\text { References } & 329\end{array}$ 


\title{
Stationary populations with below-replacement fertility
}

\section{Carl P. Schmertmann *}

\begin{abstract}
BACKGROUND

A population with sustained below-replacement fertility and constant immigration eventually becomes stationary. Stationary-through-immigration (SI) populations have unusual age structures that depend on the distribution of immigrants' arrival ages.
\end{abstract}

\section{OBJECTIVE}

I summarize known formal relationships between the distribution of immigrants' entry ages and the long-run size and structure of SI populations. I clarify a previously published result about SI dependency ratios.

\section{RESULTS}

The long-run size and age structure of an SI population depend on the remaining life expectancies of arriving immigrants, but are also sensitive to the expected numbers of native children born after arrival. Numerical calculations with contemporary Austrian data show (1) contrary to previously published results, immigration flows need not be concentrated in early working ages in order to ensure low overall dependency, and (2) the SI dependency ratio is minimized when all immigrants are in their mid-30s.

\footnotetext{
${ }^{*}$ Center for Demography and Population Health, Florida State University. E-mail: schmertmann@ @su.edu.
} 


\section{Relationship}

With constant immigration flows, there are an uncountably infinite number of stationary populations for any below-replacement fertility schedule $f$ and life table $l$. Each corresponds to a different pattern of age-specific annual immigrant inflows.

If

- The population is entirely female

- There is no emigration

- $l(0)=1$ and $l(a)$ is the probability of survival from birth to exact age $a$

- immigrants adopt local age-specific fertility $f(a)$ after arrival

- $I()$ is a dummy indicator function

- $\omega$ is the maximum life span

- $e(z)=\frac{1}{l(z)}\left\{\int_{0}^{\omega} I(a \geq z) l(a) d a\right\}$ is the remaining life expectancy of a $z$-yearold,

- $v(z)=\frac{1}{l(z)}\left\{\int_{0}^{\omega} I(a \geq z) f(a) l(a) d a\right\}$ is the reproductive value of a $z$-yearold,

- $R=v(0)<1$ is the net rate of reproduction

- $m(z)$ is the unchanging density of annual immigrants at arrival age $z$

then the long-run population is stationary, with age structure

$$
N^{*}(a)=\left[\int_{0}^{\omega}\left(\frac{v(z)}{1-R}+\frac{I(z \leq a)}{l(z)}\right) m(z) d z\right] l(a)
$$

and total size

$$
N^{*}=\int_{0}^{\omega}\left(\frac{e(0)}{1-R} v(z)+e(z)\right) m(z) d z
$$

\section{Proof}

With below-replacement fertility, the size and structure of the initial population has no effect in the long run, because each generation of their descendants is successively smaller $(R<1)$, in the long run approaching zero. A "stationary through immigration" (SI) population therefore contains only immigrants and their native descendants. 
Denote immigrants as generation $g=0$, their native-born daughters as $g=1$, granddaughters as $g=2$, and so forth. Consider a constant inflow of one immigrant per year at exact age $z$. This flow will eventually produce a stationary total of

$$
N_{0}^{*}(a \mid z)=\frac{I(z \leq a)}{l(z)} l(a)
$$

surviving foreign-born immigrants at age $a$. This population of z-arrivals is analogous to a standard stationary population with replacement-level fertility (call that the $R F$ stationary population), in which the population at age $a$ is proportional to $l(a)$. In the immigration case constant entries occur by immigration rather than birth, at age $z$ rather than 0 , and the $z$-arriving subpopulation spans ages $z$ to $\omega$, rather than 0 to $\omega$. Stationarity of the foreign-born population implies that the annual number of daughters born per $z$-arriving immigrant, $B_{1}^{*}(z)$, will eventually become stationary at

$$
B_{1}^{*}(z)=\int_{0}^{\omega} N_{0}^{*}(a \mid z) f(a) d a=\int_{0}^{\omega} \frac{I(z \leq a)}{l(z)} f(a) l(a) d a=v(z)
$$

By the same reasoning, annual granddaughters born per $z$-arriving immigrant, $B_{2}^{*}(z)$, will eventually become stationary at

$$
B_{2}^{*}(z)=\int_{0}^{\omega} B_{1}^{*}(z) f(a) l(a) d a=\int_{0}^{\omega} v(z) f(a) l(a) d a=R v(z)
$$

Repeating this calculation for great-granddaughters, etc. produces the identity

$$
B_{g}^{*}(z)=R^{g-1} v(z) \quad g=1,2,3, \ldots
$$

Because $R<1$, the total number of annual births of native descendants, per unit inflow of immigrants at age $z$, converges to

$$
B^{*}(z)=\sum_{g=1}^{\infty} B_{g}^{*}(z)=\sum_{g=1}^{\infty} R^{g-1} v(z)=\frac{v(z)}{1-R}
$$

and the density of $a$-year-olds in the stationary population resulting from each $z$-arrival is

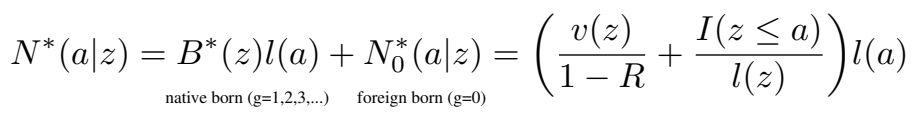


Integrating over the numbers of immigrant arrivals at each age $z$ yields the stationary density:

$$
\begin{aligned}
N^{*}(a) & =\int_{0}^{\omega} N^{*}(a \mid z) m(z) d z \\
& =\int_{0}^{\omega}\left[\left(\frac{v(z)}{1-R}+\frac{I(z \leq a)}{l(z)}\right) l(a)\right] m(z) d z \\
& =\int_{0}^{\omega}\left[\left(\frac{v(z)}{1-R}+\frac{I(z \leq a)}{l(z)}\right) m(z) d z\right] l(a)
\end{aligned}
$$

Integrating over age and reversing the order of integration yields the total population

$$
\begin{aligned}
N^{*} & =\int_{0}^{\omega} N^{*}(a) d a \\
& =\int_{0}^{\omega}\left[\int_{0}^{\omega}\left(\frac{v(z)}{1-R}+\frac{I(z \leq a)}{l(z)}\right) m(z) d z\right] l(a) d a \\
& =\int_{0}^{\omega}\left[\left(\frac{v(z)}{1-R}\right) \int_{0}^{\omega} l(a) d a+\int_{0}^{\omega}\left(\frac{I(z \leq a)}{l(z)}\right) l(a) d a\right] m(z) d z \\
& =\int_{0}^{\omega}\left[\left(\frac{e(0)}{1-R}\right) v(z)+e(z)\right] m(z) d z
\end{aligned}
$$

$Q E D: 2$

\section{History and related results}

Espenshade, Bouvier, and Arthur (1982) first demonstrated that below-replacement fertility and constant immigration streams lead to stationary SI populations. Arthur and Espenshade (1988) showed that the total size of such an SI population was very sensitive to the age distribution of annual immigrant arrivals $m(z)$.

Later studies investigated the structure of SI populations in more detail. Mitra (1990) noted that an SI population could have an age structure unlike that of the standard textbook stationary population with replacement fertility, because stationary population size would not necessarily decrease with age. Schmertmann (1992) generalized Mitra's results, and clarified how SI age structure, population size, and vital rates are related to the distribution of immigrants' entry ages. Schmertmann (1992) also showed that any SI population must be at least as old as (i.e., first-order stochastic dominant over) the replacement-fertility stationary population with the same life table. Feichtinger and Steinmann (1992) used a 
discrete version of the SI model to analyze relationships between immigrant entry ages and the proportion of an SI population that is foreign-born.

$\mathrm{Wu}$ and $\mathrm{Li}$ (2003) investigated SI dependency ratios. They concluded that, although SI populations are always older than the RF stationary population, their overall dependency ratios [(children plus retirees) / workers] could be lower than RF populations, provided that immigrant entries were concentrated around the beginning of working life.

Recent research by Feichtinger and colleagues (e.g., Dawid et al. 2009) on the age structures of organizations has investigated related questions, using optimal control models to derive entry age distributions that maximize various demographic objectives for the resulting stationary population. These organizational models are a special case of SI populations in which there is no age-specific fertility or reproduction.

\section{Numerical examples: Austria}

Relationships (1) and (2) are useful for analyzing the effects of various immigrant entry age distributions on long-run population structure. For numerical illustrations I use contemporary data from Austria, disaggregated by single year of age, $a=0,1, \ldots, 110$. Life table $l_{a}$ and ${ }_{1} L_{a}$ values come from period schedules for Austrian females in 2008 (Human Mortality Database [HMD] 2011). Current female population counts by age are from the HMD Austria 2009. Fertility rates $f_{a}$ are period-by-age data for Austria 2008 (Human Fertility Database [HFD] 2011). Daughter-only fertility rates are assumed to be (100/205) $f_{a}$ to account for the sex ratio at birth. Female immigration levels by age are from Austria in 2010 (Statistik Austria 2011), with totals for five-year age groups distributed uniformly across single years of age within the group. These data, and an $\mathrm{R}$ program for replicating calculations and plots, are available in supplementary files published with this article.

Relationship (1) allows direct calculation of the stationary population implied by Austria's current vital rates and age-specific immigration levels. Figure 1 illustrates the consequences of four different arrival age distributions for Austria's long-run population. Each panel shows 2008 female population (grey line), annual immigrant arrivals (small histogram), and the long-run stationary population associated with the arrival age distribution (dark line). In each example the total volume of annual immigration equals the 2010 value of 46155 , so that differences between panels are entirely due to differences in immigrants' arrival ages. 
Panels A-D represent four examples of age-specific immigration policies:

A. Identical to that observed in Austria 2010

B. Concentrated entirely between ages 11-29, with most immigrants near 20

C. Concentrated entirely between ages 21-39, with most immigrants near 30

D. 30-40 year olds are admitted, with their children, from populations with twice current Austrian fertility (thus, on arrival they have $2 \mathrm{x}$ as many children/woman as Austrians of the same age; after arrival they immediately adopt Austrian fertility levels)

All four stationary age distributions in Figure 1 have similar humped shapes, with a single peak. Because of the integral term in square brackets in (1), all four examples look quite different from a textbook stationary population in which $N^{*}(a) \propto l(a)$.

As demonstrated by Arthur and Espenshade (1988), total stationary population size is sensitive to the immigrants' arrival age distribution. In these examples, Austria's female population would have limiting values between 6.4 million (Panel C) and 10.6 million (Panel B). The large variations in final population size arise almost entirely from differences in reproductive value between younger and older immigrants. In Austria for example, each additional child born after immigration eventually adds $e(0) /(1-R) \approx 260$ people to the stationary population.

\section{Applications}

One important application is studying immigration's effects on dependency ratios. Relationships (1) and (2) are theoretical and apply only in the very long run. However, they are a useful starting point for understanding the potentially significant effects of immigration policy on national age structure.

For example, to what extent can countries with below-replacement fertility use agetargeted immigration policies to raise the proportion of the population in working ages? Under what conditions do such immigration policies produce lower dependency ratios than replacement fertility? Wu and $\mathrm{Li}$ (2003) raised these important questions and arrived at an interesting result. They concluded that the proportion in working ages (e.g. 20-64) is higher in an SI population than in an RF population with the same mortality schedule, provided that immigrants arrive mostly around the youngest working age.

Relationship(1) and the numerical examples presented here show that $\mathrm{Wu}$ and Li's (2003) conclusion about concentrating immigrants in young working ages needs modification. Such concentration is a sufficient, but not a necessary, condition for a lower-thanRF dependency ratio. In the Austrian case, for example, ${ }_{45} L_{20} / T_{0}=53.0$ percent of an RF population would be 20-64 years old. All four SI examples in Figure 1 have higher 
fractions in this age group, as indicated by the "\% workers" data in the panel titles. This occurs even when the $\mathrm{Wu}$ and $\mathrm{Li}$ condition is not satisfied (Panels $\mathrm{C}$ and $\mathrm{D}$ ).

Figure 1: $\quad$ Austrian 2008 female population (grey), and stationary populations with 46155 annual immigrants and varying distributions of arrival ages (black). TFR=1.41, $R=0.68, e_{0}=83$. Panel A: observed 2010 immigrant distribution. B: All immigrants arrive at ages 11-29 with most near 20. C: All immigrants arrive at ages 2139 with most near 30. D: 30-40 year old immigrants arrive from a country with 2x Austrian fertility, bring their children, and adopt Austrian fertility levels after arrival. Small histograms represent immigrant flows, (x10 to increase readability)

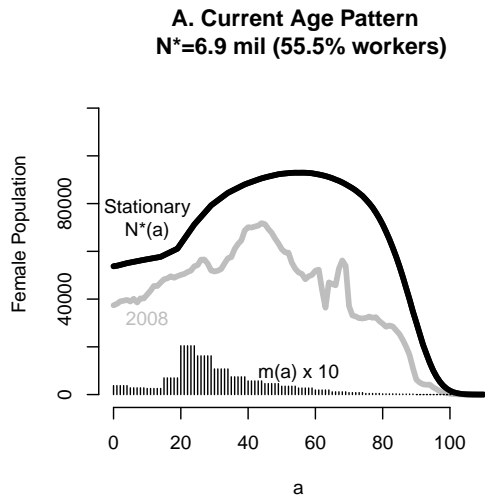

C. Arrivals Near 30 $\mathrm{N}^{*}=6.4 \mathrm{mil}(56.9 \%$ workers)

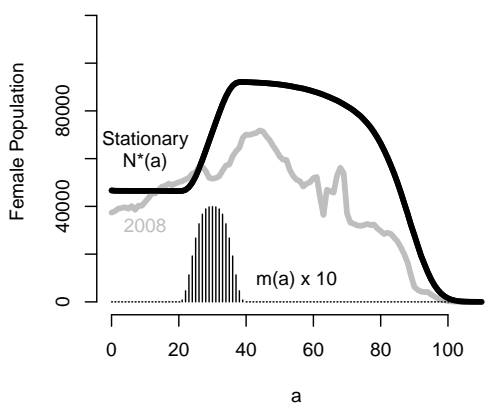

B. Arrivals Near 20

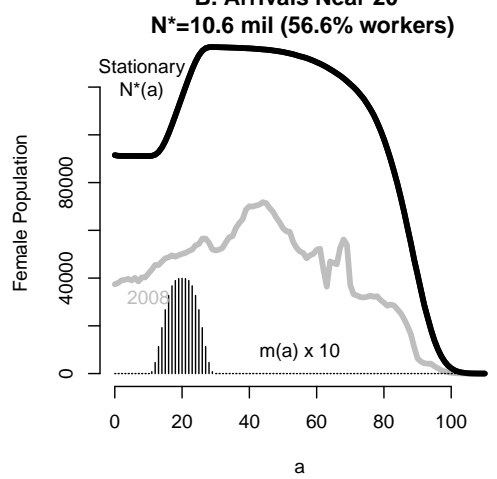

D. Immigrants $30-40+$ Own Children $\mathrm{N}^{*}=8.0 \mathrm{mil}(54.8 \%$ workers)

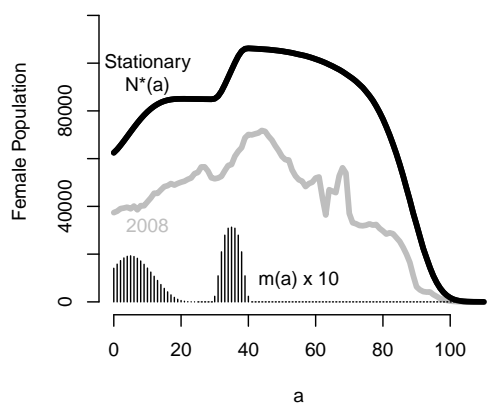


A variant of Relationship (2) gives the stationary number in working ages, which is useful for analyzing dependency in more detail. Define a dummy variable $w(a)=I(20 \leq$ $a \leq 65)$ and define $e_{w}(z)=\left(\int w(a) l(a) d a\right) / l(z)$ as the number of working years expected after entry at age $z$. Following the same logic as in the proof of Relationship (2), the stationary number of workers is therefore

$$
N_{W}^{*}=\int_{0}^{\omega} w(a) N^{*}(a) d a=\int_{0}^{\omega}\left[\frac{e_{W}(0)}{1-R} v(z)+e_{W}(z)\right] m(z) d z
$$

and the stationary proportion in working ages is

$$
\frac{N_{W}^{*}}{N^{*}}=\frac{\int_{0}^{\omega}\left[\frac{e_{W}(0)}{1-R} v(z)+e_{W}(z)\right] m(z) d z}{\int_{0}^{\omega}\left[\frac{e(0)}{1-R} v(z)+e(z)\right] m(z) d z}=\frac{\int_{0}^{\omega} F(z) m(z) d z}{\int_{0}^{\omega} G(z) m(z) d z}
$$

where $F(z) \geq 0$ and $G(z)>0$ are age-specific functions that depend on the definition of working ages, and on fertility and mortality schedules. This proportion can be rewritten as a weighted mean

$$
\frac{N_{W}^{*}}{N^{*}}=\int_{0}^{\omega} \gamma(z) \frac{F(z)}{G(z)} d z
$$

with non-negative weights $\gamma(z)=G(z) m(z) / \int_{0}^{\omega} G(z) m(z) d z$. Consequently, the stationary proportion in working ages is maximized if all immigration is concentrated as closely as possible to the $z$ value at which $F / G$ is a maximum (or, if the maximum is not unique, then to any $\mathrm{z}$ values at which $F / G$ is a maximum).

Figure 2 illustrates the $F / G$ function for the Austrian case and provides some insight about the underlying demographic processes. In Figure 2 the uppermost curve represents the proportion of the long-run foreign-born population in working ages if immigrants arrive at a single age $z$. This is maximized, as $\mathrm{Wu}$ and $\mathrm{Li}$ (2003) suggest, when immigrants are concentrated at the youngest working age. The native-born stationary population will have a proportion working, $e_{W}(0) / e(0)$, that is independent of immigration policy; for the Austrian case this is ${ }_{45} L_{20} / T_{0}=53.0 \%$, shown in the lower dashed line of Figure 2. The total proportion working in the SI population will be a weighted average of the foreign- and native-born proportions working. In Figure 2 the total proportion working corresponds to the upper middle curve if immigrant fertility is identical to Austrian native fertility after arrival, and to the lower middle curve if immigrant fertility is 1.50 times native fertility at all ages after arrival. 
Figure 2: $\quad$ Proportion of the foreign-born, native-born, and total SI stationary population in working ages when immigrants are admitted exclusively at age $z$, at contemporary Austrian vital rates. Maximum for the total stationary population occurs at $\mathrm{z}=34$ if immigrants immediately adopt native fertility on arrival (upper middle curve), or at $\mathrm{z}=\mathbf{3 5}$ if immigrant fertility is $\mathbf{1 5 0 \%}$ of native fertility at all ages after arrival (lower middle curve).

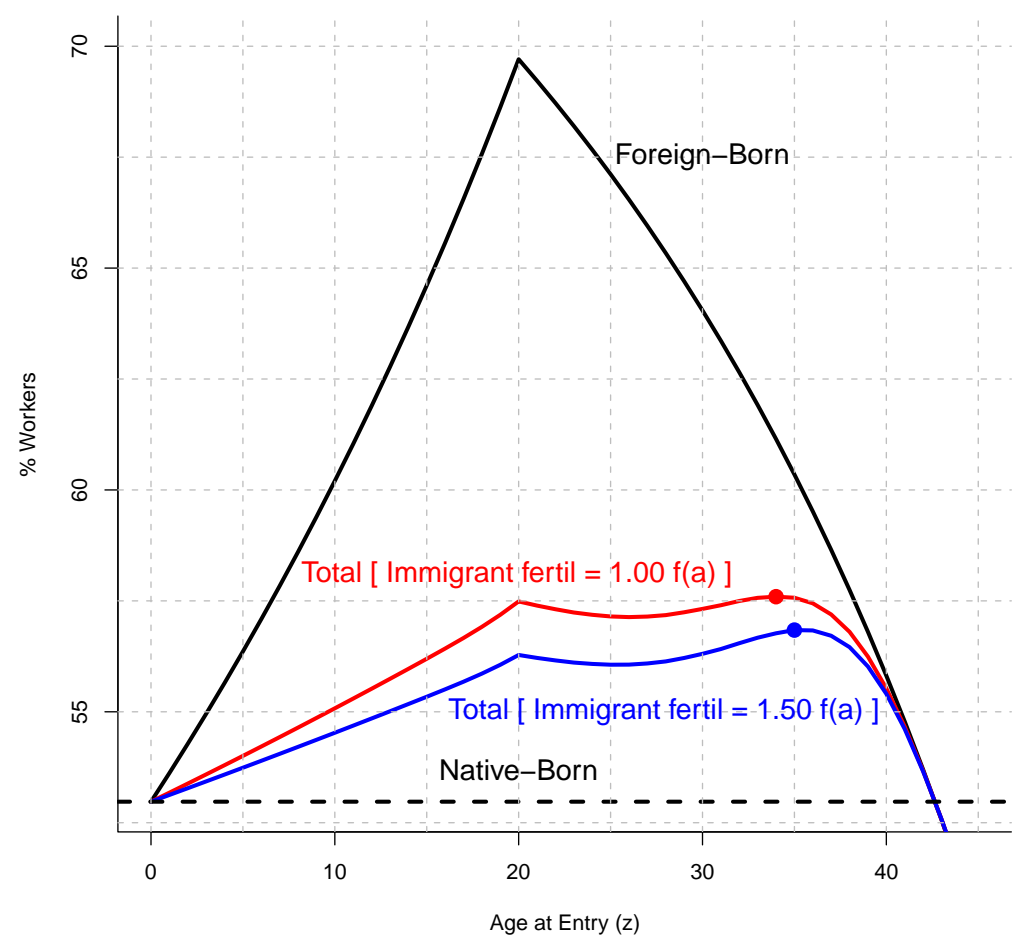

The key point is that the proportion of the SI population that is foreign-born depends on immigrants' ages: admitting older immigrants with lower reproductive values $v(z)$ will make the stationary population more foreign. In Figure 2 this corresponds to an overall proportion of workers that is closer to the uppermost curve. Over some age ranges, in particular 25 to 35 , the SI proportion in working ages can therefore increase with $\mathrm{z}$ - if 
the long-run proportion foreign rises enough to compensate for the falling (but higherthan-native) proportion of workers among the foreign-born.

The result for Austria is a long-run maximum proportion in working ages if $z=34$ (or $z=35$ if immigrants have $150 \%$ of native fertility at each age). This is far from the beginning of working life. From the upper middle curve in Figure 2, the highest possible proportion of workers in an SI population for Austria occurs if all immigrants are 34 years old on arrival: this stationary population would have 4.0 million females, with $57.6 \%$ in working ages. One can also see from Figure 2 that immigration flows at all ages less than 43 produce stationary populations with higher proportions of workers than the RF stationary population (in which the population is $100 \%$ native-born and $53.0 \%$ are in working ages).

The Austrian example shows that it is not necessary to concentrate immigrant inflows near age 20 to get a lower long-run dependency ratio. Compared to a return to replacement fertility, in Austria an SI population with any distribution of immigrant arrival ages over 0-43 will produce an equal or higher proportion in working ages and a lower dependency ratio. In other low-fertility countries with similar vital rates, results would be similar.

\section{Acknowledgements}

This research was supported by the Austrian Science Fund (FWF): Age Structured Populations with Fixed Size [P20408-G14]. I thank Gustav Feichtinger and participants at the December 2010 Vienna Workshop on Optimal Fertility for helpful comments. 


\section{References}

Arthur, W. and Espenshade, T. (1988). Immigration policy and immigrants' ages. Population and Development Review 14(2): 315-326. doi:10.2307/1973574.

Dawid, H., Feichtinger, G., Goldstein, J., and Veliov, V. (2009). Keeping a learned society young. Demographic Research 20(22): 541-558. doi:10.4054/DemRes.2009.20.22.

Espenshade, T., Bouvier, L., and Arthur, W. (1982). Immigration and the stable population model. Demography 19(1): 125-133. doi:10.2307/2061132.

Feichtinger, G. and Steinmann, G. (1992). Immigration into a population with fertility below replacement level - the case of germany. Population Studies 46(2): 275-284. doi:10.1080/0032472031000146236.

Human Fertility Database (2008). http://www.humanfertility.org (13 May 2011).

Human Mortality Database (2011). http://www.mortality.org (13 May 2011).

Mitra, S. (1990). Immigration, below-replacement fertility, and long-term national population trends. Demography 29(4): 595-612. doi:10.2307/2061854.

Schmertmann, C. (1992). Immigrants' ages and the structure of stationary populations with below-replacement fertility. Demography 29(4): 595-612. doi:10.1080/08898480306715.

Statistik Austria (2011). Außenwanderung 2010 nach Alter, Geschlecht und Staatsangehörigkeit. http://www.statistik.at/web_de/static/aussenwanderung_2010_nach_alter_ geschlecht_und_staatsangehoerigkeit_022925.xlsx (16 November 2011).

$\mathrm{Wu}, \mathrm{Z}$. and Li, N. (2003). Immigration and the dependency ratio of a host population. Mathematical Population Studies 10(1): 21-39. doi:10.1080/08898480306715. 
Schmertmann: Stationary populations with below-replacement fertility 